\title{
Constructional Changes of Chinese Lai/Qu in Serial Verb Constructions
}

\author{
Xu Yang \\ College of International Studies, Southwest University, Chongqing, China \\ Email: byyanyxu@sina.com
}

Received 29 April 2015; accepted 18 June 2015; published 24 June 2015

Copyright (c) 2015 by author and Scientific Research Publishing Inc.

This work is licensed under the Creative Commons Attribution International License (CC BY). http://creativecommons.org/licenses/by/4.0/

(c) (i) Open Access

\begin{abstract}
Directional verbs are widely used in modern Chinese. Their constructional changes can be traced back to the Directional Serial Verb Construction in old Chinese. In this paper, we investigate the constructional changes of Chinese lai and $q u$ from the pre-Qin period to the Medieval period from the perspective of constructionalization. This research demonstrates the following findings: Chinese Lai changes into directional verbs. The meaning of directional result constructionalizes the meaning of arrival state, but also persists the meaning of directional time and the causative meaning. Lai undergoes the changes from time deixis to state of affairs in the Medieval period. Chinese $q u$ changes into an intransitive verb and denotes the meaning of getting to somewhere. After a series of constructional changes, Chinese $q u$ produces a new type node and denotes a new meaning. This research proposes that the constructionalization of Chinese lai and $q u$ in SVCs is driven by the principle of economy, and the mechanisms of metaphor and metonymy.
\end{abstract}

\section{Keywords}

Directional Verbs, $\mathrm{Lai} / \mathrm{Qu}$, Constructionalization, Constructional Changes

\section{Introduction}

Directional verbs are a small subclass in modern Chinese. Their constructional changes can be traced back to the Directional Serial Verb Construction in old Chinese. Verbs lai 来 and $q u$ 去 are the most typical and pervasive words in this construction. Their use frequency is rather high. They function as predicates and complements in the construction and express the directional meaning and the extended meaning. Directional verbs contain single direction verbs and compound direction verbs. They combine with other verbs to form single direction constructions and compound direction constructions, such as $\mathrm{V}+$ lai, $\mathrm{V}+q u, \mathrm{~V}+$ shanglai 上来, $\mathrm{V}+$ chulai 出来, etc. Lai and qu can occur before or after other verbs or verb phrases. Directional verbs refer to the direc- 
tion of accomplishing an action. These words can appear by themselves, or work together with other verbs, to indicate direction, space, development and changes of things. The Chinese lai and qu include these features, such as directional, transitive, causative, auxiliary, non-directional, complemental, metaphorical and temporal meaning. When it comes to the constructional changes of lai and $q u$, we explore that the form-meaning of lai and $q u$ changes equally in the framework of constructionalization theory.

\section{Literature Review}

Many linguists have addressed to the directional verbs. As to lai and qu, they mainly focus on the different positions of directional verbs. The majority of researches agree that lai expresses the direction to a center, while $q u$ conveys the direction away from the center. In modern Chinese, they are used as directional complements extensively. Here we survey some of the most representative research.

Ding (1980) suggests that the directional verb lai refers to coming, and that qu involves leaving and going. Lai and qu can be put either before or after other verbs, or both before and after other verbs in a construction, as is shown in (1).

(1) a) 我去买书

Wo qu mai shu

I am going to buy a book

b) 我买书去

Wo mai shu $q u$

I am going to buy a book

c) 我去买书去

Wo qu mai shu $q u$

I am going to buy a book

Ding assumes that lai and $q u$ in Chinese directional SVC present the constructional change and they lose their original meaning. Lai and qu grammaticalize to be the functional words and likewise their form and meaning change. The position of directional verbs lai and $q u$ is rather flexible in the construction context.

$\mathrm{Lv}$ (1980) indicates that there are four types of construction related to qu construction. The first type is $\mathrm{V}+q u$ $+\mathrm{N}$. Here, $\mathrm{N}$ is mainly related with objects and $q u$ can be put before or after the object. In the second type $\mathrm{V}+$ $q u+\mathrm{N}, \mathrm{N}$ also refers to objects, but it is different from the first type. If quantifiers in this construction are employed as objects, only these verbs, such as yong 用, zha 占, chi 吃, and hua 花 can be used as predicate. The third type includes sui 随 or rang 让 + small clause + qu, indicating the meaning of doing something at one's convenience. The fourth type contains the construction of kanqu 看去 and tingqu 听去. They constitute a verb phrase with the meaning of evaluation and emphasis. Lai also occurs in four constructions. The first one is $\mathrm{V}+$ lai $+\mathrm{N}$ ( $\mathrm{N}$ refers to objects). In this construction, quantifiers can be used as objects. The second one includes $\mathrm{V}$ $+l a i+\mathrm{V}+q u$. The third is $\mathrm{V}+d e$ 的 or $b u$ 不 + lai. The last one is the compound constructions, including kanlai 看来, shuolai 说来, etc. This kind of words can be regarded as expressing mental activities, with the meaning of evaluation and emphasis. In a word, qu expresses the meaning of departing from the speaker while lai indicates the meaning of moving towards the speaker.

Based on Lv's study, Zhang (1991) suggests that there are four types of sentence patterns in term of the different positions of the objects in a construction. These sentence patterns include $\mathrm{VC}_{1} \mathrm{C}_{2} \mathrm{O}, \mathrm{VC}_{1} \mathrm{OC}_{2}, \mathrm{VOC}_{1} \mathrm{C}_{2}$ and $b a$ 把 $\mathrm{OVC}_{1} \mathrm{C}_{2} . \mathrm{C}_{2}$ refers to the verbs lai and $q u$, O refers to the object, $\mathrm{C}_{1}$ refers to other verbs. It is generally agreed that $b a$-construction does not belong to a subclass of SVCs, but there exist some semantic and syntactic correlations between $b a$ and other verbs in SVCs. These four types of sentence patterns express the similar sense, but the order of each component is not the same. Zhang believes that when the fourth type can be used, a patient object or an agent object participates.

$\mathrm{Lu}$ (1993) explores the semantic and syntactic features of directional verb qu. The construction of $q u+\mathrm{VP}$ is rather simple and the construction of VP+qu is complicated. The two constructions VP + qu and $q u+\mathrm{VP}$ can be replaced by each other if they express the similar inner semantic features, as is shown in (2).

(2) a) 我寄封信去

Wo ji feng xin qu

I go to post a letter

b) 我去寄封信 
Wo qu ji feng xin

I go to post a letter

However, Lu also proposes that the form of qu + VP can't be replaced by the form VP + qu in the same syntax context, as is shown in (3):

(3) a) 我去问清楚

Wo qu wen qingchu

I will go and ask what is happening

b) 我问清楚去

Wo wen qingchu qu

I will go and ask what is happening

In the construction (3), qu wen qingchu cannot be replaced by wen qingchu qu. The construction of (3) a) and b) are not the same. In (3), a) wen qingchu belongs to verb complement.

Liu (1998) explains that the verbs lai and $q u$ as directional complements are freely combined with shang 上 and xia 下. For example, 上去 go up and 下来 come down. When directional verbs lai and qu are put after the intransitive verb, they are restricted in syntactic context, typically zou 走 and pao 跑, as is shown in (4):

(4) 她向公园走去

Ta xiang gongyuan zou qu

She is going towards the park.

When directional verbs lai and qu are put after the verbs duan 端 and $n a$ 拿, there is no NP between the verbs, as is shown in (5).

(5) 你拿去吧!

Ni na qu ba!

You take it!

He also suggests that lai and qu can constitute three constructions if there are NPs in the sentence patterns. These patterns are shown in (6).

(6) 他要下楼去

Ta yao xia lou qu

He will go down the stairs

Wen (2007) employs the conceptualizer and the dominion to come up with a directional event descriptive framework. Wen suggests that a typical motion event should include figure, ground, path, motion, conceptualizer, dominion and reference point. He points out that the speaker can choose an appropriate reference point based on the following cognitive and pragmatic factors: 1 ) whether the speaker in inclusive or exclusive in the dominion; 2) whether the figure refers to the person or other entities; 3) considering the relation between the figure and ground and between the time of utterance and the ending time of the figure's motion. Pragmatic and cognitive reference point can well account for the directional verbs of lai and qu because this construction implies different pragmatic meaning and cognitive construe, as is shown in (7).

(7) 我们老师明天会来办公室

Women laoshi mingtian hui lai bangongshi

Our teacher will come to office tomorrow.

In the example (4), there are at least four interpretations: 1) the speaker is in the office at the time of utterance; 2) the speaker will be in the office at the reference time (tomorrow); 3) the addressee is in the office at the time of utterance; 4) the addressee will be in the office at the reference time, but may not be there at the reference time.

In a word, previous studies about the directional verbs lai and qu have been explored from the perspectives of syntactic level and pragmatic explanation. These researches cannot explain the motivations of change lai and $q u$, and cannot pay attention to the meaning and form of change lai and $q u$ in the constructional framework equally. When it comes to the constructional change of lai and $q u$, we explore that the form-meaning of lai and $q u$ change equally in the framework of constructionalization theory.

\section{Theoretical Foundation}

Directional verbs in Chinese have undergone great changes in both meaning and form. It is necessary to adopt 
some explanatory theories abroad for exploring the constructional changes of Chinese lai and qu. Constructionalization theory equally focuses on the changes of form and meaning and is expounded in detail by Traugott and Trousdale (2013).

\subsection{The Main Ideas of Constructionalization Theory}

Language change has been addressed from both synchronic and diachronic perspective by several current researchers in cognitive linguistics. The main figures who have made great contributions to this field are Goldberg (2006), Langacker (2008), Croft (2005), Traugott and Trousdale (2013) and Hilpert (2013). Constructionalization theory addresses the change in the linguistic system and focuses on the creation of and the nature of changes in constructions. Within the framework of Construction Grammar, two main types of changes have been paid attention to, namely constructional changes and constructionalization.

1) Constructional changes refer to such changes that "affect features of an existing construction, e.g. semantics, morphophonology, collocational constraints, etc. These changes do not necessarily lead to a new construction”. These changes are called constructional changes by Traugott and Trousdale (2013: p. 1).

2) Constructionalization refers to "the creation of a form new-meaning new pairing" (ibid).

Traugott and Trousdales' purpose is to show how a constructional perspective can be used to rethink and incorporate aspects of prior work on grammaticalization and lexicalization. Constructional approaches to language adhere to general principles of cognitive linguistics. Although there exist some differences among current constructional approaches to language, Goldberg (2013) has identified the following sharing tenets:

1) The basic unit of grammar is the construction while the construction is a conventional pairing of form and meaning.

2) Semantic structure can be mapped directly on to surface syntactic structure and there is no the process of derivations.

3) Language is regarded as a network of nodes and links between nodes; these associations between nodes take the form of inheritance hierarchies.

4) Cross-linguistic variation can be accounted for from domain-general cognitive processes.

5) Language structure is shaped by language use.

These constructional approaches consider grammar as holistic framework. These factors including semantics, morphosyntax, phonology, and pragmatics function together in a construction.

\subsection{Two Models of Constructionalization}

Two main models of constructionalization are grammatical constructionalization and lexical constructionalization. Grammatical constructionalization focuses on the constructional development through a series of smallstep changes and brings about a form ${ }_{\text {new }}$-meaning $_{\text {new }}$ sign. The constructional approach suggests that the models of reduction and expansion are not in conflict but complementary to one another. Grammatical constructionalization involves an increase in schematicity and productivity and a decrease in compositionality. Lexical constructionalization is addressed to how some new contentful constructions form and develop. It focuses on some gradual constructionalization of schema and instantaneous creation of new micro-nodes. Traugott and Trousdale (2013: p. 193) propose that there exist main differences between lexical and grammatical constructionalization: "the output of lexical constructionalization is contentful and the output of grammatical constructionalization is procedural”. Lexical and grammatical constructionalization may be gradual, but in lexical constructionalization, such as word-formation, can also be instantaneous. A constructional approach unifies the studies in grammaticalization and lexicalization, establishing the theoretical framework of constructionalization.

\subsection{The Context for Constructionalization}

Context is an important factor in the process of constructional change. The function of contexts is much different prior to and after constructionalization. Replication of pragmatic and morphosyntactic contexts can prompt for constructional changes and constructionalization. The context usually refers to the local network context, but the pre-constructionalization changes are generally related with genre or text type. Post-constructionalization new construction types may be derived from the schematic template. Constructions in the network with similar meaning and form are regarded as important contextual factors and they can serve as models or attractors. Criti- 
cal contexts may persist both at the item-specific level and at the schematic level. Persistence can be accounted from the structural level and semantic level.

\section{The Constructional Changes of Chinese Lai and $Q u$}

The lai and qu of the pre-Qin period are different from the directional verbs in the modern Chinese. The lai and $q u$ of modern Chinese can collocate with the locative objects while the lai and qu of the pre-Qin period cannot collocate with any locative objects. The lai and $q u$ in the pre-Qin period express the state of arriving. Its critical period of constructional changes is in the Han dynasty. According to the research (2007), lai begins to change into directional complements, dynamic auxiliaries, aspectual particles in the Northern and Southern Dynasties. These changes do not appear in the pre-Qin period.

\subsection{The Constructional Changes of Chinese lai in the Pre-Qin Period}

Lai can be served as a predicate or as the first component in SVCs. The popular usage is found in the Analects of Confucius, which is shown in (8).

(8) 有朋自远方來, 不亦乐乎? (“论语·学而”)

What a joy it is to have friends coming from afar. (It is derived from the learning of Analects).

Lai in this period can be used in the three aspects: It directly collocates with the subject, modifies the prepositions and follows the causative objects.

Lai also expresses the directional meaning, which is based on the extension of the meaning of arriving, showing the motion in space. Hence, the directional meaning forms in this period, as is shown in (9).

(9) 由周而来, 七百有余年矣. (“孟子·公孙丑下”)

It has been more than seven hundred years to come the sage since the Zhou Dynasty. (It comes from Gong Sun Chou II, Menci).

In the example (9), lai mainly denotes the time locations of things or persons and forms the time locus and the direction which are from far to near. The time locus is derived from the metaphor of space trajectory.

\subsection{The Constructional Changes of Lai in the Medieval Period}

Lai in the Medieval period brings about great changes and occurs in the second component in SVCs, as is shown in (10).

(10) 犬即奔往入水, 湿身走来卧处. (“搜神記” 卷二十)

The dog is running into a stream, jumping into the water to wet its whole body, and going back the previous place in which $\mathrm{Li}$ is sleeping. (It is derived from twenty volumes, Stories of Immortals).

In the example (10), lai is used as the second component to form the compound verb, which can collocate with the locative objects. Lai changes into the directional verbs. The meaning of directional result constructionalizes the meaning of arrival state, but also persists the meaning of directional time and the causative meaning.

The change of Lai in the Medieval period undergoes from time deixis to state of affairs. The time deixis 以来 (since) mainly refers to the time of duration, but the time start and the time end are determined by their collocative components .

\subsection{The Constructional Changes of Chinese $Q u$}

The semantic overgeneralization of Chinese $q u$ can be classified into two stages: the first stage is to express the meaning of leaving (离开), removing and distance in the pre-Qin period, as is shown in the (11) and (12).

(11) 逝将去女, 适彼乐土. (“诗经·魏风.硕鼠”)

I swear that I have to leave you and go to another paradise. (It is derived from Shuo Su, Wei Feng, The Book of Poems)

(12) 孔子曰: “禄之去公室, 五世矣”. (《论语·季氏》)

Confucius said: "Lu was losing the state power for five generations". (It is derived from Ji Shi, The Analects).

The meaning of leaving is the earliest and basic and other meanings are generalized according to the basic 
meaning. The foundation of common semantic is distance motion which is relative to the reference point. In the example (12), qu loses some motion meanings, denoting to a kind of distance motion through certain reference point, only expressing a directional action.

The second stage takes place in Han and Wei Dynasty. From the beginning of this period, qu expresses the meaning of arriving or going (到/往), as is shown in (13).

(13) 阿母谓阿女: “汝可去应之”. (“孔雀东南飞”)

Mrs Liu said to her daughter: "You can go there to promise him". (It originates from Peacock Flies towards Southeas).

$Q u$ changes into an intransitive verb and cannot follow the object in the example of (13). With its use increasing, qu comes into being low transitivity and denotes the meaning of getting to somewhere at this period. After a series of changes, qu produces a new type node and takes place the constructionalization.

\section{The Lai and Qu Motivations of Consructionalization}

\subsection{The External Factors Lai and Qu Constructional Changes}

The lai and qu constructional changes can be explained from the linguistic principle of economy. This principle focuses on the relation between the rank of a word and its frequency use first and another argument in the principle as certain compromise between the force of unification and the force of diversification. For example, a speaker who attempts to solve his immediate problems will balance these against the background of the probable future problems. He will try his best to solve problems in such a way as to minimize the whole work that he must expend in solving both his immediate problems and his probable future problems. That in turn means the speaker will attempt to minimize the probable average rate of his work-expenditure. In this way, he minimizes his effort and forms the simplified constructions.

According to Zipf (1949), the main concept of economy, a tenet or tendency shared by the living organisms, can be referred to as the principle of least effort, which consists in tending towards the minimum amount of effort that is necessary to realize the maximum utility. This principle operates in linguistic behavior at the constructional changes.

In the field of language use, Zipf (1949) points out the two competing forces: the force of unification, or speaker's economy, and the force of diversification, or the hearer's economy. The first force is a drive toward simplification. The second force is an anti-ambiguity principle, which would lead to a situation where a constructional meaning is expressed through the use of different words. The reality of this course is a compromise between the two forces. One word may express different meanings, which is called polysemy. A constructional meaning can be achieved by means of employing the different words, which is called synonymy.

Lai and qu abide by the principle of economy in the constructional changes. From the synchronic aspect, lai and $q u$ increase their senses of a dictionary and enlarge their scopes of use. From the diachronic perspective, lai and $q u$ in SVCs can simplify their construction by means of constructionalization context, namely the construction lai/qu $+\mathrm{V}+\mathrm{O}$ can simplify lai/qu $+\mathrm{O}$, as is shown in (14) a) and (14) b):

(14) a) 咱们来做个爽快

b) 咱们来个爽快(means that let's just have fun).

In a word, the constructional meanings of lai and $q u$ are driven by the principle of economy. We can consider the principle of economy as external dynamical factors for constructionalization.

\subsection{The Internal Mechanism of Lai and Qu Constructional Changes}

Metaphor is everywhere in our languages. The function of metaphor is to understand and experience one kind of thing by means of another. Metaphor is considered to be an ontological mapping from the source domain to the target domain. Metaphors run through the people's conceptualization and are grounded in human's experience for the physical world. Metonymy is also regarded as a cognitive process. This process contains one conceptual entity and the vehicle and can provide mental access to another conceptual entity or the target in the same domain.

The lai and qu constructional changes are closely associated with metaphor and metonymy. Metaphor plays an important role in the constructional changes of lai. And it can be considered as the internal change mechan- 
ism. Lai constructional changes do not fully imply the speaker's place displacement, but mainly focus on the speaker's motion of subjective images. Sometimes, the constructional changes also display displacement of mental imagery. This kind of displacement follows the projection path from the concrete displacement domain to the abstract displacement domain. Metonymy can be better explained the constructional changes of $q u$. They are mainly reflected in the constructional changes from the leaving meaning to the arriving meaning. These meaning changes ascribe to metonymy, namely from the concepts of one conceptual domain to another related domain. Metonymy can be regarded as the qu internal mechanism of constructional changes.

\section{Conclusion}

In this paper, we investigate how the Chinese lai and qu take place the constructional changes from the pre-Qin period to the Medieval period from the perspective of constructionalization. The research demonstrates the following findings. Firstly, lai changes the directional verbs. The meaning of directional result constructionalizes the meaning of arrival state, but also persists the meaning of directional time and the causative meaning. The changes of Lai in the medieval period undergo from time deixis to state of affairs. Secondly, qu changes into an intransitive verb and cannot follow the object. With its usage increasing, qu comes into being low transitivity and denotes the meaning of getting to somewhere at this period. After a series of changes, qu produces a new

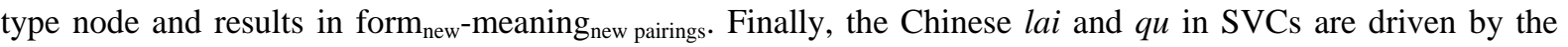
principle of economy and the mechanisms of metaphor and metonymy.

\section{Funding}

This paper is financed by the Project of Doctoral Candidates' Scientific Research Innovation from Chongqing Education Commission. NO. CYB14063.

\section{References}

Ding, S. S. (1980). Lectures on Modern Chinese Grammar. Beijing: The Commercial Press.

Liu, Y. H. (1998). General Explanation about Chinese Directional complements. Beijing: Beijing Language and Culture University Press.

Lu, J. M. (1993). Discussion about Modern Chinese Syntax. Beijing: The Commercial Press.

Lv, S. X. (1980). Modern Chinese Eight Hundred Words. Beijing: The Commercial Press.

Wen, X. (2007). Pragmatic Meaning and Deictic Conditions of the Motion Verbs Lai and Qu. Foreign Language Teaching and Research, 2, 91-96.

Zhang, B, J. (1991). Object Position Constraint in the Directional Construction. Chinese Language Learning, 6, 4-8.

Zipf, G. K. (1949). Human Behavior and the Principle of Least Effort. Cambridge, MA:Addison-Wesley. 